\title{
Effect of Different Shell Materials on the Mechanical and Thermal Properties of Core-Shell Structured Bamboo- Plastic Composites
}

\author{
Yu Xian, ${ }^{\mathrm{a}, \mathrm{b}}$ Cuicui Wang, ${ }^{\mathrm{b}}$ Ge Wang, ${ }^{\mathrm{b}}$ Leemiller Smith, ${ }^{\mathrm{c}}$ and Haitao Cheng ${ }^{\mathrm{b}, *}$
}

The purpose of the study was to inspect the mechanical and thermal properties of four kinds of core-shell structured bamboo-plastic composites (BPCs). The materials that were used for the fabrication of the BPCs were high density polyethylene (HDPE), bamboo pulp fibers (BPF)/HDPE, nano- $\mathrm{CaCO}_{3} / \mathrm{HDPE}$, and white mud (WM)/HDPE. As verified by flexural properties and impact properties, the dispersion of the $\mathrm{BPF}$, nano- $\mathrm{CaCO}_{3}$, and WM in the HDPE matrix was inhomogeneous. The fracture surface of the scanning electron microscope (SEM) images showed that some aggregates existed in the HDPE. Additionally, X-ray diffraction (XRD) was used to corroborate the results. The thermogravimetric analysis (TGA) showed that the samples with the WM/HDPE shell has little effect on the thermal stability. However, the apparent activation energy $\left(E_{\mathrm{a}}\right)$ values of the nano- $\mathrm{CaCO}_{3} / \mathrm{HDPE}$ shell were higher than those of the other samples, which indicated better thermal stability. The thermal stability had no remarkable changes with the addition of the WM and BPF. The differential scanning calorimeter (DSC) curves revealed that the relative crystallinity of the BPCs increased with the addition fillers, which suggested that the fillers can act as nucleating agents.

Keywords: Core-shell structure; Bamboo plastic composites; Mechanical properties; TG; DSC; Kinetic

Contact information: a: The College of Forestry, Shanxi Agricultural University, Taigu, Shanxi, China; b: Key Laboratory of National Forestry and Grassland Administration/Beijing for Bamboo \& Rattan Science and Technology, International Centre for Bamboo and Rattan, Beijing, P. R. China, 100102; c: Mechanical Energy Engineering Department, University of North Texas, Denton, TX 76207-7102, USA;

* Corresponding author: htcheng@icbr.ac.cn

\section{INTRODUCTION}

Wood plastic composites (WPCs) are a new type of environment-friendly products, which are composed of wood fibers, thermoplastic resins, compatibilizers, coupling agents, and fillers. WPCs are used in the auto industry, residential products, and many other applications with growing markets ( $\mathrm{Li}$ and $\mathrm{Wu}$ 2013; Ritu et al. 2017). Extrusion is a mature technology used in the production of WPCs (Askanian et al. 2015). Co-extrusion has become an advanced modern plastic molding method to manufacture WPCs. The coextrusion method is used to create multilayer WPCs with different complementary layer characteristics (Mei et al. 2017).

Polyethylene (PE), polypropylene (PP), and polyvinylchloride (PVC) are the most commonly used plastic matrices in the manufacturing of WPCs. Fillers are needed to improve the appearance and the physical and mechanical properties of the final WPCs. Fillers are minerals such as calcium carbonate $\left(\mathrm{CaCO}_{3}\right)$, talc, and montmorillonite. A number of studies have shown that mineral fillers have a positive impact on the flexural 
strength and moisture resistant properties of WPCs (Nikolaeva and Kärki 2012; Li et al. 2013; Koohestani et al. 2017). Some studies have demonstrated that core-shell structured WPCs had reduced moisture uptake compared to non-coextruded products, which indicated that the core-shell structured WPCs showed better water resistance properties and color stability (Jin and Matuana 2010; Butylina et al. 2015; Nikolaeva and Kärki 2016). The physical and mechanical performance of the core-shell structured WPCs were significantly better than their core-only controls. The effect of wood loadings in the shell layer, the shell thickness, and the quality of the core layer on the mechanical and water absorption properties of the core-shell structured WPCs were also studied. The results showed that co-extrusion technology can significantly reduce the manufacturing costs and improve the functionality of WPCs (Yao and Wu 2010). It was reported that coextruded WPCs filled with silane-treated precipitated $\mathrm{CaCO}_{3}$ and wood fiber in the shells had reduced water absorption and thermal expansion values (Kim et al. 2013). Despite their advantages, WPCs have poor interfacial compatibility between the wood fiber and polymer matrix (Zhang et al. 2004; Lin et al. 2014; Ou et al. 2014). However, the use of fillers has made it difficult to obtain good dispersion and strong interfacial adhesion, which can affect the interfacial compatibility between the core and shell layer of structured WPCs. The fillers conversely undergo aggregation in the shell layers, which will negatively impact the properties of core shell structured WPCs (Kord 2011).

In recent years, the demand for the wood and wood-based composites in various applications has increased despite limited forest resources. On the other hand, bamboo is an abundant and fast-growing species primarily found in China. Currently, bamboo has a wide range of applications in many fields, such as bamboo pulp, bamboo fiber for textiles, bamboo-based panels, bamboo charcoal, etc. (Peng and She 2014). Bamboo residue fibers (BRF) and white mud (WM) are the solid residues that are generated from the primary processing and alkali recovery during the bamboo pulping process. The BRF byproduct contains mostly cellulose, hemicellulose, and lignin. The WM is very difficult to dispose due to the large number of silicon ions it contains, so WM often ends up in landfills (Liao et al. 2012). Currently, $\mathrm{CaCO}_{3}$ is commonly used as filler for plastics and WPCs. It has been found that $\mathrm{CaCO}_{3}$ can improve the mechanical properties of plastics and WPCs, but it had reduced the impact strength. Core-shell structured WPCs with HDPE shell layer were found to have decreased overall composite modulus. The WM byproduct is a chemical substance made up of $\mathrm{CaCO}_{3}$ (Huang et al. 2015; Xian et al. 2015). So, the BRF and WM can also be applied to fabricate core-shell structured bamboo plastic composites (BPCs). The preparation of the core-shell structured BPCs is an advanced utilization of bamboo pulp and paper residues. The thermal stability and mechanical properties of core-shell structured BPCs are very important for its application. However, relatively few studies have reported the thermal stability properties of core-shell structured BPCs. Wu et al. (2014) found that the linear coefficient of thermal expansion (LCTE) values of co-extruded WPCs with a basalt fiber/high density polyethylene (HDPE) composite shell were significantly lower than that of neat HDPE shell materials. Vassiliou et al. (2010) and Gao et al. (2013) studied the effect of organically modified montmorillonite, fumed silica nanoparticles, and nano- $\mathrm{CaCO}_{3}$ on the physical properties and thermal degradation kinetics of polyethylene terephthalate (PET). The results showed that the nanocomposites containing $\mathrm{CaCO}_{3}$ had a higher apparent activation energy than the pure PET, demonstrating that the addition of the nanoparticles can help improve the thermal stability of composites.

However, there has been little research on the effect of different shell layer 
materials on the mechanical and thermal properties of composites. Therefore, research on the kinetics of the thermal decomposition behavior of core-shell structured BPCs has not been carried out. In this study, core-shell structured BPCs containing different shell materials were prepared by co-extrusion. Four different shell layers were prepared: HDPE, nano- $\mathrm{CaCO}_{3} / \mathrm{HDPE}, \mathrm{WM} / \mathrm{HDPE}$, and $\mathrm{BPF} / \mathrm{HDPE}$. The objective of this study was to investigate the effects of the shell layer materials on the mechanical and thermal properties of core-shell structured BPCs. In particular, the apparent activation energy of the core-shell structured BPCs was calculated via a model of the kinetics of the thermal decomposition.

\section{EXPERIMENTAL}

\section{Materials and Preparation}

All the raw materials that were used in this study are summarized in Table 1. All the materials were dried at $80{ }^{\circ} \mathrm{C}$ for $24 \mathrm{~h}$ before being used. A twin-screw extruder was used to granulate for the core and shell layer systems. The optimization parameters of the co-extrusion process were $150{ }^{\circ} \mathrm{C}, 160{ }^{\circ} \mathrm{C}, 165^{\circ} \mathrm{C}, 175^{\circ} \mathrm{C}$, and $150{ }^{\circ} \mathrm{C}$ (die). A mixture of HDPE and BRF were used for the core systems. The materials used for the shell were $\mathrm{HDPE}, \mathrm{BPF} / \mathrm{HDPE}$, nano- $\mathrm{CaCO}_{3} / \mathrm{HDPE}$, and WM/HDPE. The abbreviations for the four core-shell structured BPCs were CSHDPE, CSBPF, CSNano-CaCO 3 , and CSWM, respectively. The formulation information of the core-shell structured BPCs can be seen in Table 2.

Table 1. Raw Materials used in the Work

\begin{tabular}{|c|c|c|c|}
\hline Material & Characteristics & Function & Supplier \\
\hline BRF & 25 to $425 \mu \mathrm{m}$ & $\begin{array}{l}\text { Core layer } \\
\text { material }\end{array}$ & $\begin{array}{l}\text { Guizhou Chitianhua } \\
\text { Co., Ltd. (Chishui, } \\
\text { China) }\end{array}$ \\
\hline BPF & $\begin{array}{l}\text { Chemical pulping, } \\
\text { length } 1146 \mu \mathrm{m}\end{array}$ & $\begin{array}{l}\text { Filler in Shell } \\
\text { layer }\end{array}$ & $\begin{array}{l}\text { Guizhou Chitianhua } \\
\text { Co., Ltd. (Chishui, } \\
\text { China) }\end{array}$ \\
\hline WM & $\begin{array}{l}\text { Mean grain size was } \\
12.125 \mu \mathrm{m}\end{array}$ & $\begin{array}{l}\text { Filler in Shell } \\
\text { layer }\end{array}$ & $\begin{array}{l}\text { Guizhou Chitianhua } \\
\text { Co., Ltd. (Chishui, } \\
\text { China) }\end{array}$ \\
\hline Nano- $\mathrm{CaCO}_{3}$ & $40 \mathrm{~nm}$ & $\begin{array}{c}\text { Filler in Shell } \\
\text { layer }\end{array}$ & $\begin{array}{l}\text { Beijing Boyu High-tech } \\
\text { New Material } \\
\text { Technology Co., Ltd. } \\
\text { (Beijing, China) }\end{array}$ \\
\hline PE-Wax & Density: $0.945 \mathrm{~g} / \mathrm{cm}^{3}$ & Lubricant & $\begin{array}{c}\text { Yi-li Chemical Reagent } \\
\text { Company (Beijing, } \\
\text { China) }\end{array}$ \\
\hline HDPE (DGDK-3364) & $\begin{array}{c}\text { Density: } 0.945 \mathrm{~g} / \mathrm{cm}^{3}, \\
\text { melt index: } \\
0.75 \mathrm{~g} / 10 \mathrm{~min}\left(190{ }^{\circ} \mathrm{C},\right. \\
2.16 \mathrm{~kg}) \text {, tensile } \\
\text { strength of } \mathrm{HDPE} \text { was } \\
22.1 \mathrm{MPa} \text {. }\end{array}$ & Matrix & $\begin{array}{l}\text { Zhangmutou Plastic } \\
\text { Co., Ltd. (Guangzhou, } \\
\text { China) }\end{array}$ \\
\hline $\begin{array}{l}\text { Maleated polyethylene } \\
\text { (MAPE, CMG9801) }\end{array}$ & $\begin{array}{l}\text { Added in the } \\
\text { fiber/plastic blends to } \\
\text { improve the } \\
\text { compatibility }\end{array}$ & Compatilizer & $\begin{array}{l}\text { Zhang Mu Tou } \\
\text { Company Ltd. } \\
\text { (Guangzhou, China) }\end{array}$ \\
\hline
\end{tabular}


Table 2. Formulation of the Core-shell Structured BPCs

\begin{tabular}{|c|c|c|c|c|c|c|c|c|}
\hline \multirow{2}{*}{ Sample } & \multicolumn{4}{|c|}{ Shell $(w t \%)$} & \multicolumn{4}{c|}{ Core (wt\%) } \\
\cline { 2 - 7 } & HDPE & BPF & Nano-CaCO & WM & BRF & HDPE & MAPE & PE-Wax \\
\hline CSHDPE & 100 & 0 & 0 & 0 & & & & \\
\hline CSBPF & 90 & 10 & 0 & 0 & \multirow{3}{*}{30} & 6 & 4 & 1 \\
\hline CSNano-CaCO $_{3}$ & 90 & 0 & 10 & 0 & & & & \\
\hline CSWM & 90 & 0 & 0 & 10 & & & & \\
\hline
\end{tabular}

\section{The Core-shell Structured BPCs Manufacturing}

The composites were manufactured by the co-extrusion method. A $30 \mathrm{~mm}$ single screw extruder (Shanghai Sunlight Plastic Machinery Manufacturing Co., Ltd., Shanghai, China) and a $20 \mathrm{~mm}$ single screw extruder (Shanghai Sunlight Plastic Machinery Manufacturing Co., Ltd., Shanghai, China) were used to prepare the core and shell. The area of the specially designed die was $4 \mathrm{~mm}^{2} \times 30 \mathrm{~mm}^{2}$ and the shell thickness of the samples was $0.6 \mathrm{~mm}$. After the pre-experiment, the ratio rotational speed of the core-shell system was $1: 2$. The manufacturing temperatures of the core system were $160{ }^{\circ} \mathrm{C}, 165^{\circ} \mathrm{C}$, $170{ }^{\circ} \mathrm{C}, 170^{\circ} \mathrm{C}$, and $165^{\circ} \mathrm{C}$ (die). The mixing temperature for the shell system ranged from $160{ }^{\circ} \mathrm{C}$ to $180{ }^{\circ} \mathrm{C}$. The cooling method of the coextruded BPCs comprised a water tank with a controlled water spray. The extrusion speed was maintained by a speed-controlled puller.

\section{Characterization of the Core-shell Structured BPCs}

A laser particle size granularity analyzer (Mastersizer 2000, Malvern Instruments Ltd., Malvern, UK) was used to measure the particle size of the WM. The crystal structure of the HDPE, BPF, nano- $\mathrm{CaCO}_{3}$, and $\mathrm{WM}$ were analyzed with an X-ray diffractometer (Malvern Panalytical B.V., Almelo, Netherlands) with $\mathrm{Cu}$ Ka lines ( $k=1.5406 \AA$ ). The generator was utilized at $40 \mathrm{kV}$ and $40 \mathrm{~mA}$, and the diffractograms were scanned from $5^{\circ}$ to $60^{\circ}$.

\section{Mechanical properties}

To characterize the mechanical properties of the core-shell structured BPCs, six standard samples were prepared for each group according to the ASTM standard D790 (2017) at ambient temperature. The samples were testing with an Instron 5848 MicroTester (Norwood, MA, USA) at a crosshead speed of $10 \mathrm{~mm} / \mathrm{min}$. The $80 \mathrm{~mm} \times 30 \mathrm{~mm} \times 4 \mathrm{~mm}$ (length $\times$ width $\times$ thickness) samples were fabricated with a horizontal push table saw machine. The notched impact strength was performed according to the ASTM standard D6110 (2010) with a pendulum hammer impact tester (Kecheng Testing Machine Co. Ltd, Chengde, China). Five specimens were tested for each composition.

Scanning Electron Microscope (SEM) Analysis

To investigate the dispersion state of the fillers in the shell layers, the fracture morphology of the core-shell structured BPCs was observed with a JEOL 6310F fieldemission scanning electron microscope (SEM) (Tokyo, Japan). The surface was coated with a thin layer of gold under vacuum chamber before it was examined at an acceleration voltage of $7.0 \mathrm{kV}$. 


\section{Thermogravimetric analyzer (TGA)}

The thermal stabilities of the core-shell structured BPCs were tested by a Q500 thermogravimetric analyzer (TGA) (TA Instruments, New Castle, DE, USA). The weight of each composites was approximately $8 \mathrm{mg}$. Each sample was heated from $25^{\circ} \mathrm{C}$ to 800 ${ }^{\circ} \mathrm{C}$ at heating rates of $10,20,30$, and $40{ }^{\circ} \mathrm{C} / \mathrm{min}^{1}$. The thermal degradation behavior of the four core-shell structured BPCs was studied under a nitrogen atmosphere. The kinetic studies equation of samples (Mothé and de Miranda 2013) was calculated according to Eqs. 1, 2, and 3:

$$
\begin{aligned}
\frac{d \alpha}{d t} & =k f(\alpha) \\
k & =A^{\left(-\frac{E_{a}}{R T}\right)} \\
\alpha & =\frac{m_{0}-m_{t}}{m_{0}-m_{f}} \times 100
\end{aligned}
$$

where $\alpha$ is the degree of conversion (\%), $k$ is the rate constant, $f(\alpha)$ is the function of the conversion rate, which is dependent on the reaction mechanism, $A$ is the pre-exponential factor $\left(\mathrm{min}^{-1}\right), E_{a}$ is the apparent activation energy $(\mathrm{kJ} / \mathrm{mol}), R$ is the gas constant $\left(8.314 \mathrm{~J} /\left(\mathrm{mol}^{*} \mathrm{~K}\right)\right), T$ is the absolute temperature $(\mathrm{K}), m_{0}$ is the initial weight of the sample $(\mathrm{g}), m_{t}$ is the weight of the sample at temperature $T(\mathrm{~g})$, and $m_{f}$ is the final weight of the sample (g). Based on Eq. 1 introducing the heating rate, $\beta=d T / d t$, in to Eq.(1-3) is obtained as:

$$
\frac{d \alpha}{d T}=\left(\frac{A}{\beta}\right)^{\left(-\frac{E a}{R T}\right) * f(\alpha)}
$$

According to Eqs. 2 and 3, the kinetic parameters of core shell structured BPCs can be calculated based on the TGA data. In this study, the Flynn-Wall-Ozawa (FWO) method was used to calculate the apparent activation energy and frequency factor. According to the principles of this method, Eq. 5 can be obtained:

$$
\log \beta=\log \left[\frac{A E_{a}}{R f(\alpha)}\right]-2.315-\frac{0.4567 E_{a}}{R T}
$$

For a given conversion rate, a linear relationship was observed through the regression lines of $\log \beta$ vs. $1 / T$ for the four temperature heated rates. Then, the apparent activation energy $\left(E_{a}\right)$ was obtained from the slope of the curve.

\section{Differential scanning calorimeter (DSC) analysis}

The degree of crystallinity of the core-shell structured BPCs were calculated by means of the decomposed diffraction patterns from the differential scanning calorimeter (DSC) analysis (DSC Q100; TA Instruments, New Castle, DE, USA). Samples that weighed approximately $5 \mathrm{mg}$ were placed in an aluminum pan and sealed under a nitrogen flow rate of $60 \mathrm{~mL} / \mathrm{min}$ at a constant heating rate of $10{ }^{\circ} \mathrm{C} / \mathrm{min}$. The samples were cooled down to $-20{ }^{\circ} \mathrm{C}$ after $5 \mathrm{~min}$ and then heated from $-20{ }^{\circ} \mathrm{C}$ to $180{ }^{\circ} \mathrm{C}$. The samples were cooled again to $-20{ }^{\circ} \mathrm{C}$ at the same rate, maintained at that temperature for $2 \mathrm{~min}$, and heated again to $180{ }^{\circ} \mathrm{C}$ at a rate of $10{ }^{\circ} \mathrm{C} / \mathrm{min}$. The heating-cooling curve was recorded. 


\section{RESULTS AND DISCUSSION}

\section{Characterization of the Samples}

Figure 1 showed the XRD patterns for the crystalline structure and phase composition of the $\mathrm{WM}$, nano- $\mathrm{CaCO}_{3}, \mathrm{BPF}$, and HDPE. The crystal phase of the HDPE included diffraction planes of 110 and 200, which corresponded to the $2 \theta$ Bragg angles of $21.6^{\circ}$ and $24.0^{\circ}$, respectively. There were two intensity peaks, peak 1 (110) and peak 2 (200), which corresponded to the cellulose content in the BPF pattern. The WM sample had crystal planes of (012), (104), (110), (113), (202), (018), and (116), which corresponded to the diffraction angles at $2 \theta=23.10^{\circ}, 29.47^{\circ}, 36.04^{\circ}, 39.49^{\circ}, 43.24^{\circ}$, $47.63^{\circ}$, and $48.62^{\circ}$, which are consistent with a previous study (Gao et al. 2013). The average crystal size was calculated from the broadening for each diffraction peak. According to the Scherrer formula, the average crystal size of the nano- $\mathrm{CaCO}_{3}$ nanoparticles in this study was approximately $30 \mathrm{~nm}$ for the (104) diffraction peak, which is consistent with the actual size. The crystallinity of the samples can be reflected by the values of the peak's area. According to this method, the crystallinity index of the HDPE, BPF, nano- $\mathrm{CaCO}_{3}$, and WM samples were 90.4\%, 97.43\%, 78.54\%, and $73.03 \%$, respectively. In theory, the thermal stability of the composites can be improved by increasing the crystallinity index (Poletto et al. 2012). However, there are many factors affecting thermal stability of BPCs, such as the interface compatibility.

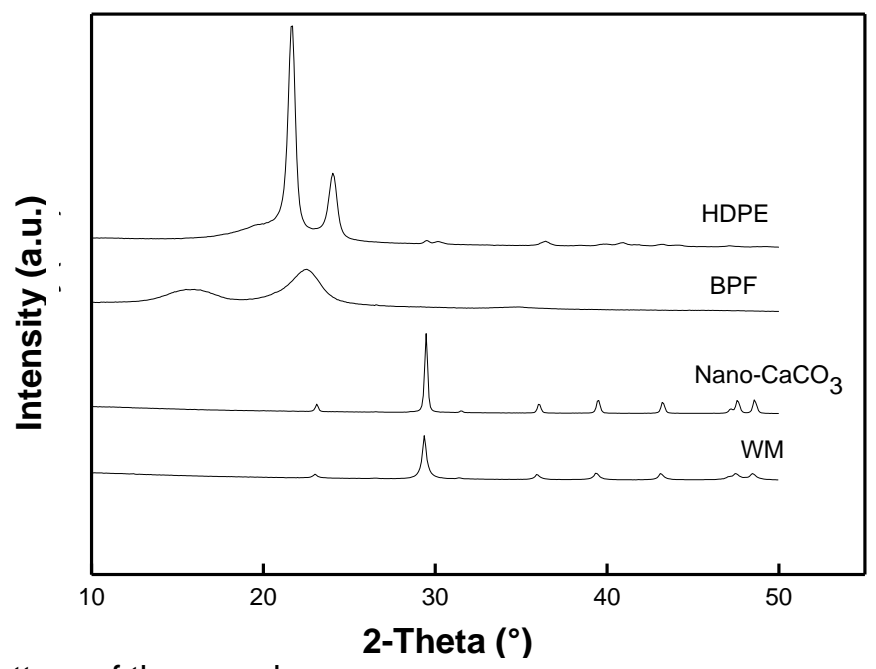

Fig. 1. The XRD pattern of the samples

\section{Mechanical Properties}

Figure 2 shows the comparative charts of the flexural strength and modulus results of the core-shell structured BPCs with the same core systems. The CSHDPE BPC exhibited the best mechanical properties, with maximum flexural strength and modulus values of 53.1 and $3543 \mathrm{MPa}$, respectively. The flexural strength and modulus of the CSBPF, CSNano- $\mathrm{CaCO}_{3}$, and CSWM BPCs decreased compared to the CSHDPE sample. The flexural strength and modulus values of the CSWM BPC decreased by $18.5 \%$ and $12.2 \%$, respectively. The experimental results indicated that the shell layer materials have a certain effect on the flexural strength and modulus of the core-shell structured BPCs. The shell layer contained virgin HDPE, which was consistent with the core layer. The deformation 
of core layer was restricted when the core-shell structured BPCs were tested during the 3point bending test. Furthermore, the flexural strength of the core-shell structured BPCs with the HDPE shell layer was higher than the other BPCs. The continuity of the BPCs was destroyed when filler was added in the shell layer, as the filler could not effectively prevent cracks from propagating. This suggested that weak interfacial bonding existed in the core and shell or in the shell alone.

The breaking energy associated with the core-shell structured BPCs was measured by the Izod and Charpy impact tests. Table 3 presents the results of the impact strength, which shows that the shell layer played an important role on the impact property of the BPCs. Table 3 shows that the BPCs with the virgin HDPE shell layer had the highest impact strength among all the BPCs. The impact strength of the BPCs with BPF, nano- $\mathrm{CaCO}_{3}$, and WM in the shell layer were lower. In general, WPCs can absorb more energy with excellent interfacial compatibility of wood flour and polymer. There was good interfacial compatibility between the virgin HDPE shell and HDPE-based core layer that forms an effective protection for the core layer of the CSHDPE sample and results in excellent impact toughness. After adding $\mathrm{BPF}$, nano- $\mathrm{CaCO}_{3}$, and $\mathrm{WM}$ in the shell layer, the interfacial compatibility between the core and shell was affected, resulting in a lower impact fracture toughness. These results are supported by other experiments about WPCs (Shi et al. 2013).

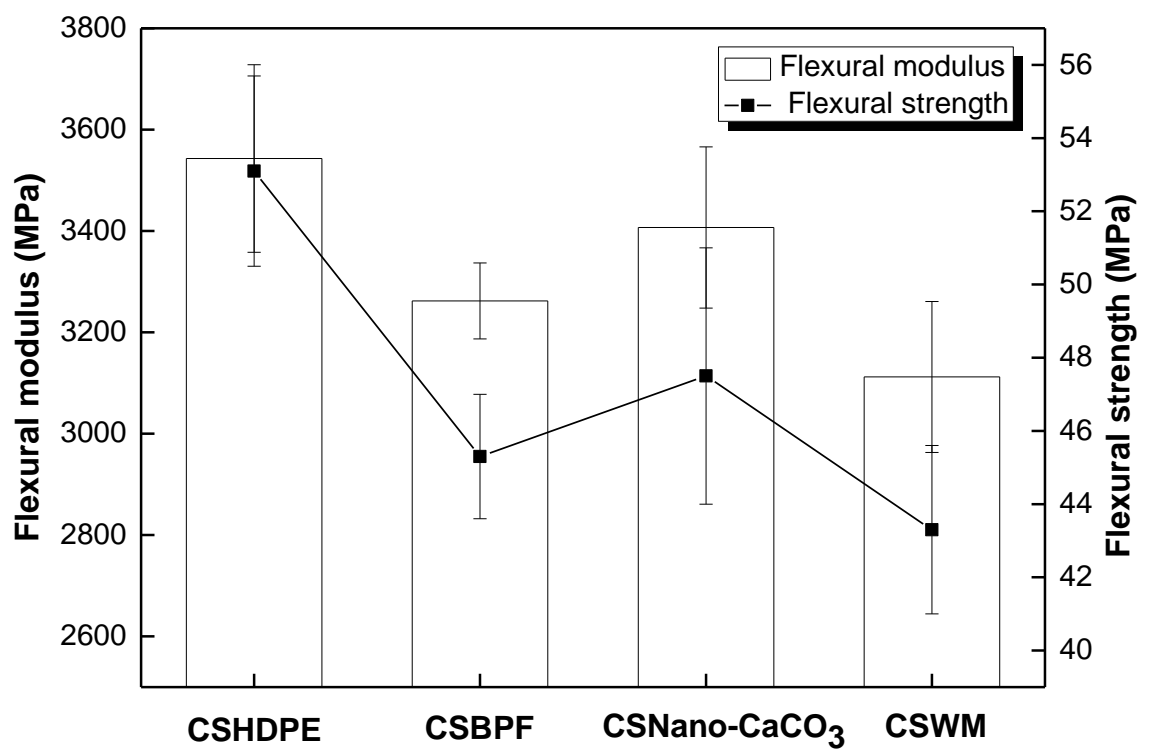

Fig. 2. Flexural mechanical properties of the core-shell structured BPCs

Table 3. Impact Strength of the Core-shell Structured BPCs

\begin{tabular}{|c|c|c|c|c|}
\hline Sample & CSHDPE & CSBPF & CSNano-CaCO & CSWM \\
\hline Impact Strength $\delta /\left(\mathrm{kJ} / \mathrm{m}^{2}\right)$ & $84.91(2.72)$ & $73.68(2.74)$ & $75.11(2.64)$ & $65.41(3.65)$ \\
\hline
\end{tabular}

Note: The values in parentheses are standard deviations

The properties of the core-shell structured BPCs were dependent on the filler's dispersion and adhesion in the polymer matrix. The interfacial morphology of the core and shell layer is an important parameter in the core-shell structured BPCs. In order to observe the dispersion of fillers in the HDPE shell layers and the interface of the core and shell 
layers, the fractured surfaces of the core-shell structured BPCs were examined via SEM (Fig. 3). The fractured section was smooth in the HDPE shell, while the addition of BPF, nano- $\mathrm{CaCO}_{3}$, or $\mathrm{WM}$ in the shell layer created some defects in the fractured section. The $\mathrm{BPF}$ pullout can be found in the fractured surface of CSBPF. When nano- $\mathrm{CaCO}_{3}$ or $\mathrm{WM}$ were added in the shell, the aggregates of the nano- $\mathrm{CaCO}_{3}$ or $\mathrm{WM}$ increased. This caused many defects and holes due to the size of the nanoparticles (approximately $40 \mathrm{~nm}$ ) and the micro/nano size of the WM particles. This indicated poor interfacial contact with the shell layer (Gao et al. 2013; Xian et al. 2015).
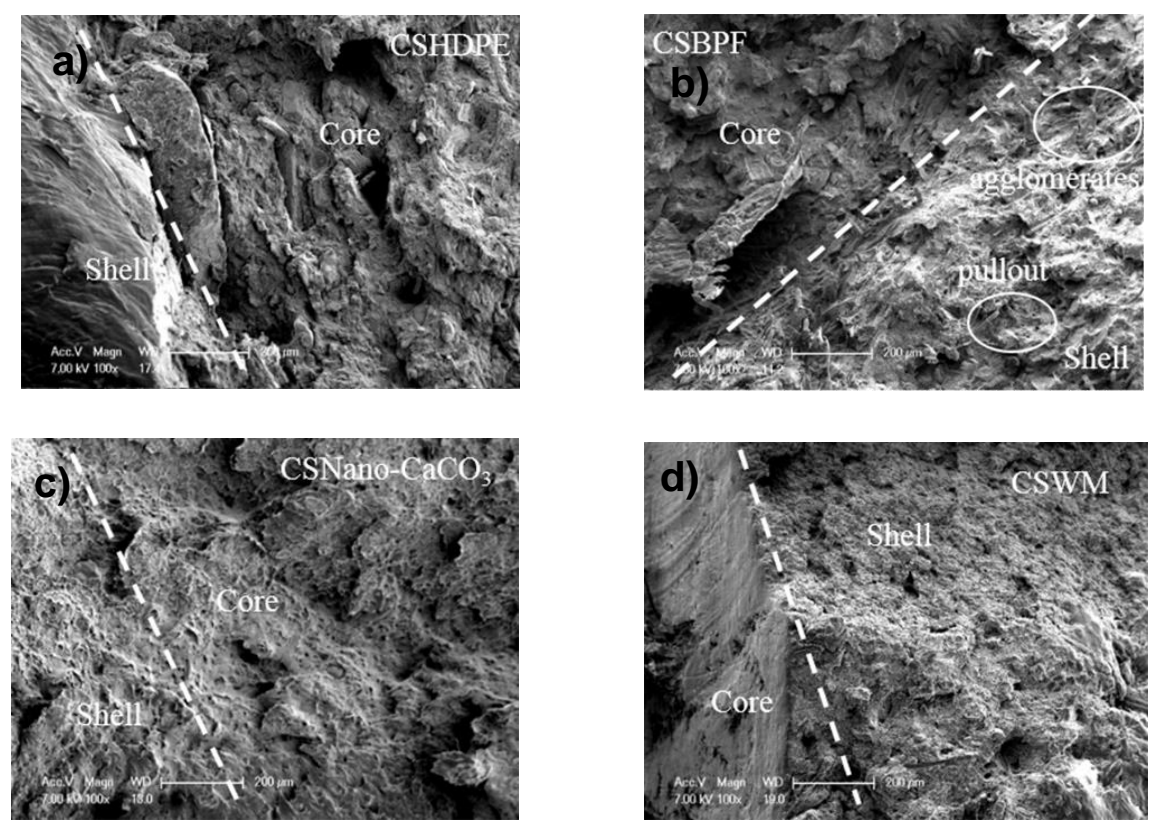

Fig. 3. SEM images of the a) CSHDPE, b) CSBPF, c) CSNano- $\mathrm{CaCO}_{3}$, and CSWM core-shell structured BPC fractures

\section{Thermal Properties}

The thermogravimetric (TG) and derivative thermogravimetry (DTG) curves of the core-shell structured BPCs are shown in Fig. 4. The thermal stability of the core-shell structured BPCs was analyzed after they were dried at $105{ }^{\circ} \mathrm{C}$ for $1 \mathrm{~h}$. The thermal degradation of all the samples occurred within the heating temperature of $800{ }^{\circ} \mathrm{C}$. The first shoulder peak was in the temperature range from $250{ }^{\circ} \mathrm{C}$ to $400{ }^{\circ} \mathrm{C}$. This may be associated the degradation of the cellulose, hemicellulose, and lignin from the bamboo residues or the bamboo pulp fibers (Ibrahim et al. 2003; Nurdina et al. 2009). The degradation of the HDPE matrix at $400{ }^{\circ} \mathrm{C}$ to $500{ }^{\circ} \mathrm{C}$ was represented in the second shoulder. The last stage was associated with $\mathrm{CaCO}_{3}$ or WM. The shape of the TG curves was similar within the programmed temperatures, which were slightly affected by the fillers in the shell layer. The core-shell structured BPCs with the nano- $\mathrm{CaCO}_{3} / \mathrm{HDPE}$ or WM/HDPE presented better thermal stability. The weight showed no remarkable change at temperatures less than 250 ${ }^{\circ} \mathrm{C}(<0.6 \%)$ compared with the HDPE or BPF/HDPE shell. As can be seen from the DTG curves, the maximum decomposition rate occurred at the temperature $T_{\mathrm{p}}$ (the peak temperature of DTG curves) $=475.4{ }^{\circ} \mathrm{C}$ for the BPCs with the HDPE shell layer. The maximum decomposition rates for the nano- $\mathrm{CaCO}_{3} / \mathrm{HDPE}$ and WM/HDPE shell layers occurred at $T_{\mathrm{p}}=477.3{ }^{\circ} \mathrm{C}$ and $478.9{ }^{\circ} \mathrm{C}$, respectively. The $T_{\mathrm{p}}$ did not increase due to the addition of nano- $\mathrm{CaCO}_{3}$ or $\mathrm{WM}$ in the shell layer. The $T_{\mathrm{p}}$ was also within the range of 
error, which indicates that the thermal stability of the BPCs was not influenced to a significant extent. These results were similar to those reported by Pal et al. (2012) and Gao et al. (2013).
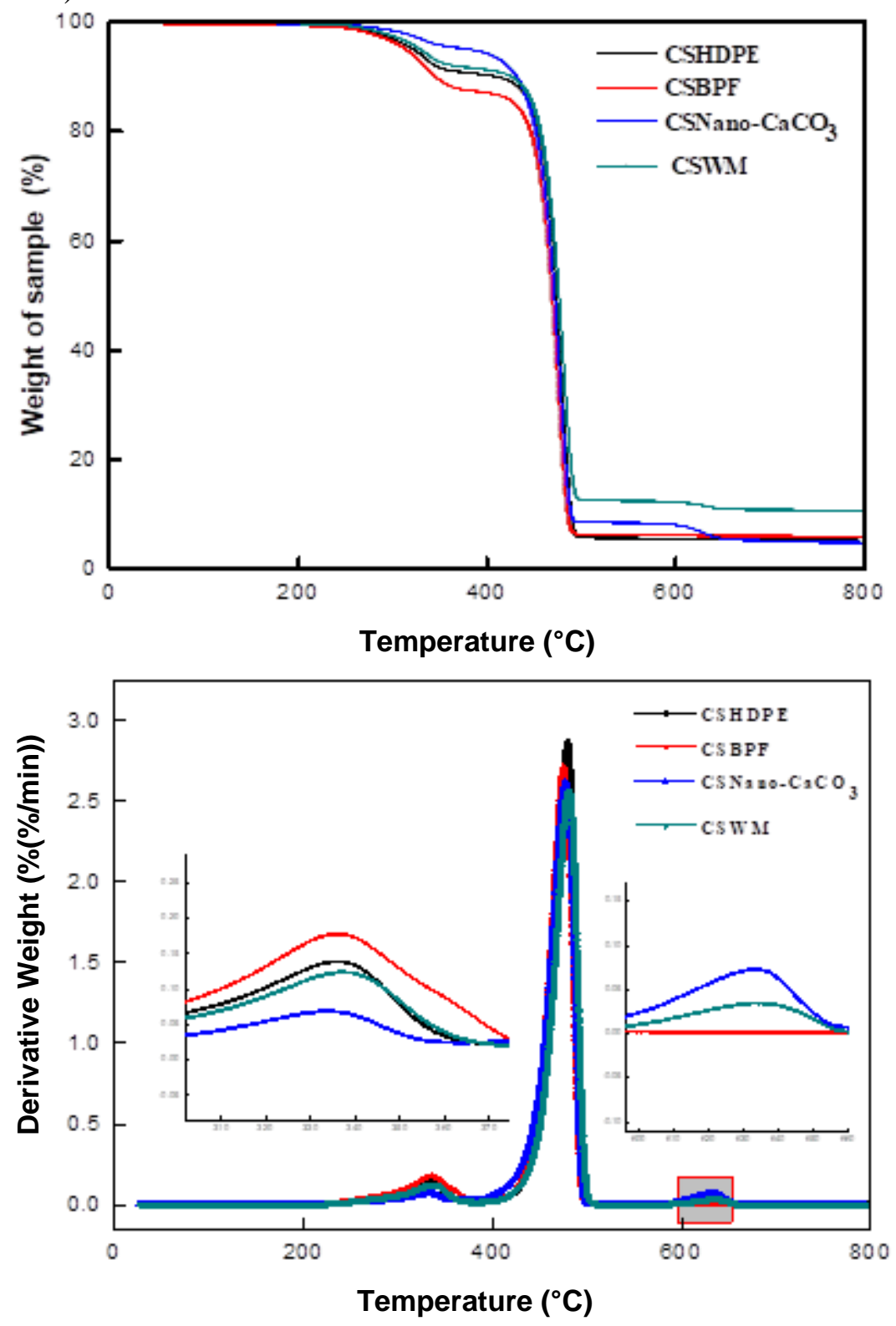

Fig. 4. TG and DTG curves of the core-shell structured BPCs

The FWO plots of $\log \beta$ versus $1 / T$ for characteristic apparent activation energy $\left(E_{\mathrm{a}}\right)$ of the core-shell structured BPCs can be seen in Fig. 5. Other studies have shown that the reaction mechanism is variable in the lower conversion region or higher conversions (Yao et al. 2008; Chen et al. 2014), so a conversion rate from 0.2 to 0.8 was selected for all the BPCs. Figure 5 displays a good fit for conversions from 0.2 to 0.8 . Figure 6 shows the $E_{\text {a }}$ for each conversion degree using the FWO method, which was calculated from the slopes of the curves. The fitted lines that were observed in the conversion range from 0.2 to 0.8 were nearly parallel. The decomposition activation energies of the core-shell structured BPCs are presented in Table 4 with the different reaction degrees. 

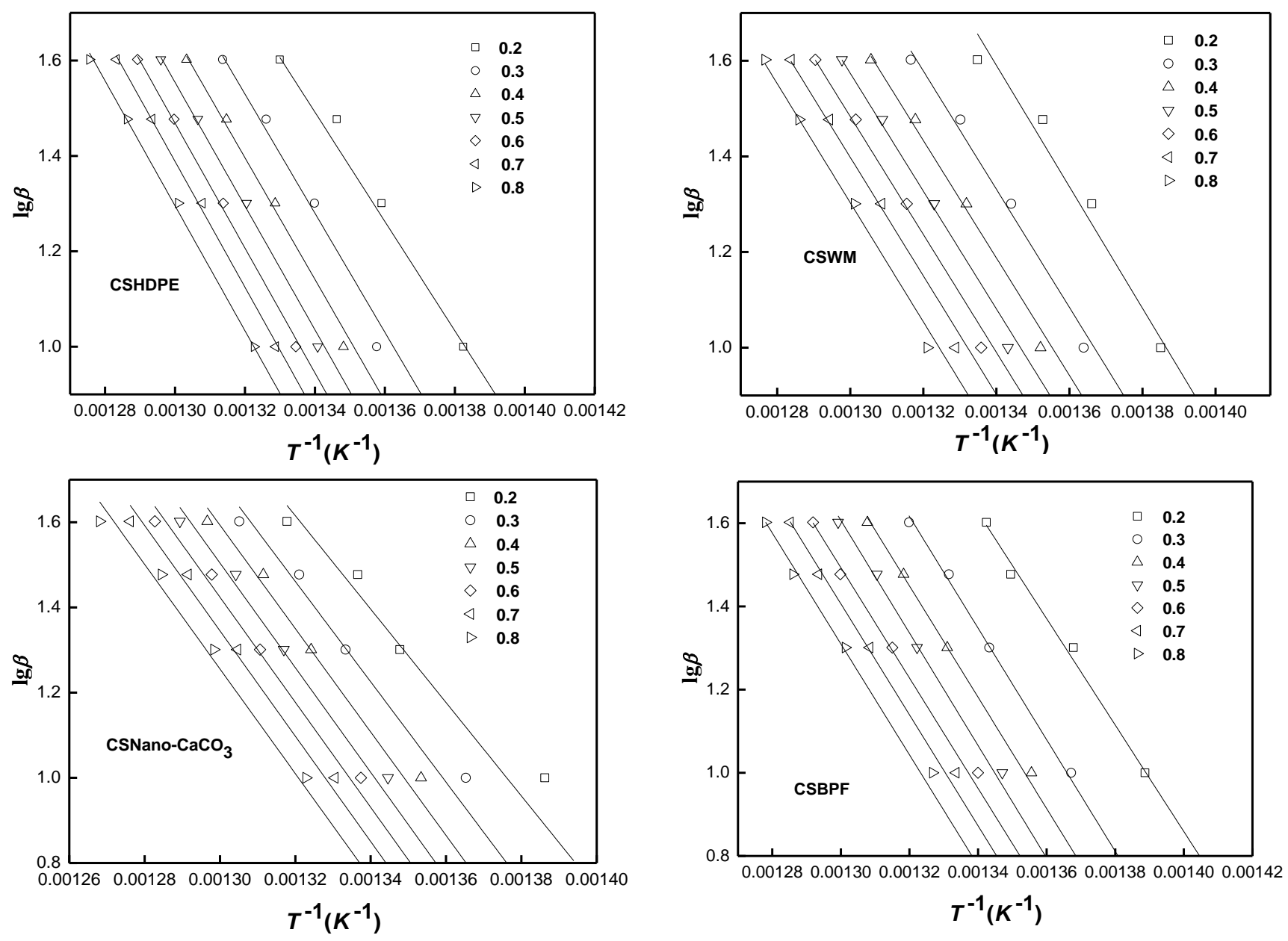

Fig. 5. The FWO plots in the 0.2 to 0.8 conversion range for the core-shell structured BPCs

Table 4. Apparent Activation Energy Media $\left(E_{\mathrm{a}}\right)$ for the BPCs

\begin{tabular}{|c|c|}
\hline Samples & $E_{\mathrm{a}}(\mathrm{kJ} / \mathrm{mol})$ \\
\hline CSHDPE & $231.64(2.77)$ \\
\hline CSBPF & $218.86(4.22)$ \\
\hline CSNano-CaCO & $242.05(1.78)$ \\
\hline CSWM & $225.87(1.14)$ \\
\hline
\end{tabular}

Note: The values in parentheses are standard deviations

The average $E_{\text {a value was }} 231.64 \mathrm{~kJ} / \mathrm{mol}$ from $\alpha=0.2$ to $\alpha=0.8$ for the core-shell structured BPCs that contained the HDPE shell layers. The average apparent activation energies of the core-shell structured BPCs increased with addition of nano- $\mathrm{CaCO}_{3}$ in the HDPE shell layer. The higher $E_{\mathrm{a}}$ values illustrated that the combustion process was more difficult for these BPCs. It was apparent that decomposition of the nano- $\mathrm{CaCO}_{3} / \mathrm{HDPE}$ shell was more difficult than the pure HDPE shell under same experimental conditions. It was concluded that the addition of the nano- $\mathrm{CaCO}_{3}$ in the shell layer could improve the thermal stability of the core-shell structured BPCs by increasing the $E_{\text {a }}$ of the composites

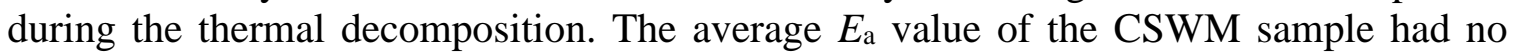
obvious change (Table 4), which may have been due to the weak bonding between the WM and HDPE in the shell (Vassiliou et al. 2008; Sanchez-Garcia et al. 2010). The BPF in the 
shell layer may have been associated with the cellulose and hemicellulose content, as these chemical substances can decompose easily at lower temperatures, accelerating the degradation process (Poletto et al. 2012). Therefore, the degradation of the HDPE may have been accelerated, which likely decreased the $E_{\text {a values. }}$

The DSC analysis was conducted for heating and cooling to investigate the effect of the different shell layers on the crystallization behaviors of the core-shell structured BPCs, as shown in Fig. 6 and Table 5.

Figure 6 shows the DSC curves of all the studied BPCs with a heating rate of 10 ${ }^{\circ} \mathrm{C} / \mathrm{min}$. The first heating cycle was intended to remove any prior thermal history that was caused in the manufacturing process of the composites. Compared to the pure HDPE, the crystallization temperatures and the melting temperatures of the core-shell structured BPCs had no apparent changes as the filler content in the shell layer increased.

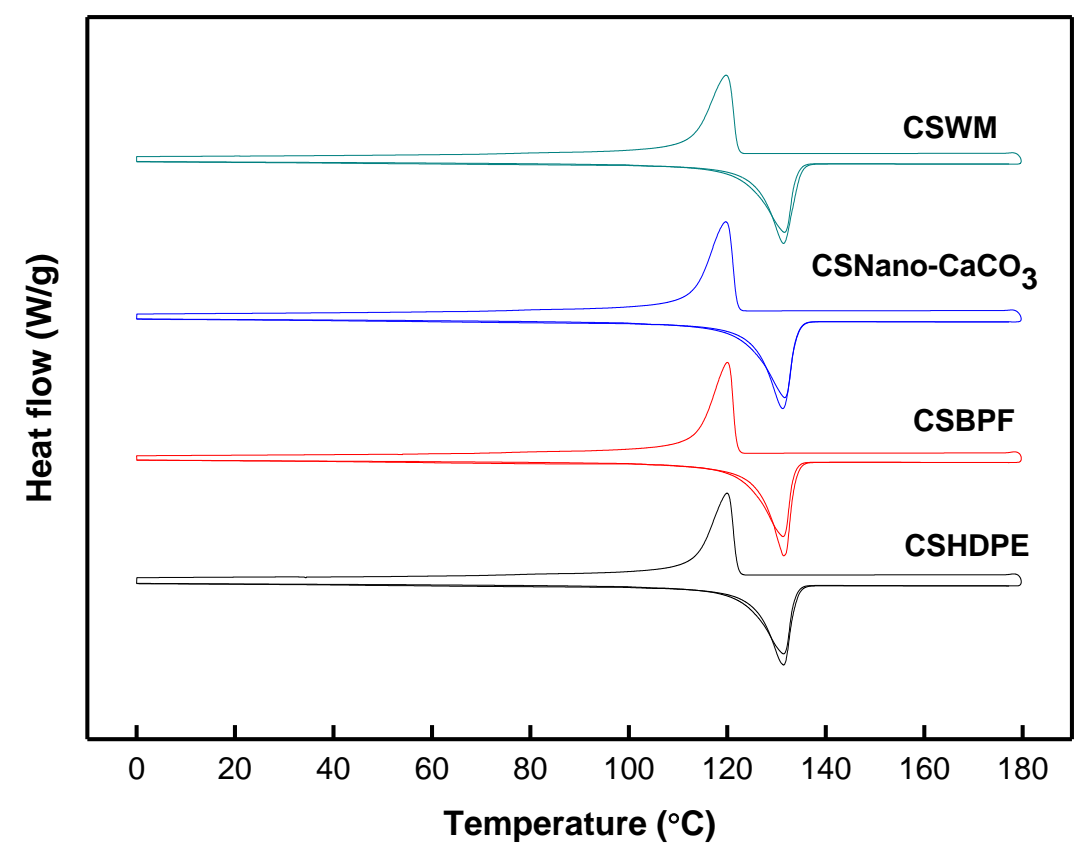

Fig. 6. The DSC thermograms of the core-shell structured BPCs with different shell layers

The results of DSC data are presented in this section.

The initial melting temperature ( $\left.T_{\text {onset }}\right)$, the peak melting temperature $\left(T_{\mathrm{m}}\right)$, the melting enthalpy $\left(\Delta H_{\mathrm{m}}\right)$, and the relative crystallinity $\left(X_{\mathrm{c}}\right)$ were the relevant values in the DSC analysis (Table 5). Based on the values, the $X_{\mathrm{c}}$ was determined according to Eq. 6 (Gao et al. 2013),

$$
X_{C}(\%)=\frac{\Delta H_{m}}{\Delta H_{f}(1-W)} \times 100
$$

where $\Delta H_{f}$ is the melting enthalpy for $100 \%$ crystalline HDPE and $W$ is the mass fraction of fillers in the core-shell structured BPCs. The $\Delta H_{\mathrm{f}}$ value was $286.7 \mathrm{~J} / \mathrm{g}$ (Xian et al. 2015). The $\Delta H_{\mathrm{m}}$ was determined from the areas of the melting peak. The $T_{\text {onset, }} T_{\mathrm{c}}, T_{\mathrm{m}}, \Delta H_{\mathrm{m}}$, and $X_{\mathrm{c}}$ values of the various core-shell structured BPCs that were calculated from the DSC curve can be seen in Table 5 . 
Table 5. Summary of the $T_{\text {onset, }} T_{\mathrm{c}}, T_{\mathrm{m}}, \Delta H_{\mathrm{m}}$, and $X_{\mathrm{c}}$ Values of the Core-shell Structured BPCs

\begin{tabular}{|c|c|c|c|c|c|c|}
\hline \multirow{2}{*}{ Samples } & \multicolumn{2}{|c|}{ Crystallize } & \multicolumn{4}{c|}{ Secondary Scan } \\
\cline { 2 - 7 } & $T_{\text {onset }}\left({ }^{\circ} \mathrm{C}\right)$ & $T_{\mathrm{c}}\left({ }^{\circ} \mathrm{C}\right)$ & $T_{\text {onset }}\left({ }^{\circ} \mathrm{C}\right)$ & $T_{\mathrm{m}}\left({ }^{\circ} \mathrm{C}\right)$ & $\Delta H_{\mathrm{m}}(\mathrm{J} / \mathrm{g})$ & $X_{\mathrm{c}}(\%)$ \\
\hline CSHDPE & 109.4 & 119.9 & 121.0 & 131.4 & 160.7 & 62.3 \\
\hline CSBPF & 109.2 & 120.0 & 121.1 & 131.8 & 172.2 & 66.7 \\
\hline $\begin{array}{c}\text { CSNano- } \\
\mathrm{CaCO}_{3}\end{array}$ & 109.3 & 119.7 & 120.8 & 131.7 & 183.3 & 71.0 \\
\hline $\mathrm{CSWM}^{\mathrm{C}}$ & 109.4 & 119.8 & 120.6 & 131.6 & 164.5 & 63.8 \\
\hline
\end{tabular}

As seen in Fig. 6 and Table 5, the relative crystallinity of the core-shell structured BPCs increased slightly with the addition of BPF, nano- $\mathrm{CaCO}_{3}$, or $\mathrm{WM}$ in the shell layer. This trend is indicative of $\mathrm{BPF}$, nano- $\mathrm{CaCO}_{3}$, or $\mathrm{WM}$ possibly playing a role in increasing the crystallinity of HDPE, where it has been suggested that the incorporation of nano$\mathrm{CaCO}_{3}$ into the HDPE increases the number of nucleation sites via the nucleation effect (Zaman et al. 2014). The WM in the shell layer can also be expected to have a crystallinity that is equal to or greater than the composites with the nano- $\mathrm{CaCO}_{3}$. This trend is indicative that the nonuniformity of the WM causes agglomeration in the shell layer because it is very difficult to disperse in the HDPE. Similar results were seen for the systems of both $\mathrm{HDPE} /$ cellulosic fiber and PET/nano- $\mathrm{CaCO}_{3}$ composites (Colom et al. 2000; Gao et al. 2013).

\section{CONCLUSIONS}

1. The analysis of the flexural and impact properties of the bamboo-plastic composites (BPCs) with the high-density polyethylene (HDPE) shell layer revealed that agglomerates and defects were formed with the addition of bamboo pulp fibers (BPF), nano- $\mathrm{CaCO}_{3}$, or white mud (WM) in the HDPE matrix.

2. Thermogravimetric analysis (TGA) demonstrated that the samples with the WM/HDPE shell did not have a major effect on the thermal stability. The activation energy $\left(E_{\mathrm{a}}\right)$ values were calculated with the Flynn-Wall-Ozawa (FWO) method. The $E_{\text {a }}$ of the nano- $\mathrm{CaCO}_{3} / \mathrm{HDPE}$ shell was higher than that of the other composite, which suggested a better thermal stability. The thermal stability slightly declined with the addition of the WM and BPF. The thermal stability values did no correlate with the degree of crystallinity of the WM and the $\mathrm{BPF}$, as previously reported in the literature.

3. The differential scanning calorimetry (DSC) curves of the core-shell structured BPCs with different shell layer materials revealed that the BPF, nano- $\mathrm{CaCO}_{3}$, or WM can act as nucleating agents that affect the degree of crystallinity.

\section{ACKNOWLEDGMENTS}

This work was supported by the National Key R\&D Program of China (Grant No. 2017YFD0600802), the foundation for the Key Laboratory of National Forestry and Grassland Administration/Beijing for Bamboo \& Rattan Science and Technology (ICBR2020-03), the foundation for Shanxi Province Excellent Doctors (SXYBKY201745), the 
Technology and Innovation Fund of Shanxi Agricultural University (2017YJ23), and the Scientific and Technological Innovation Program of Higher Education Institutions in Shanxi (2019L0395).

\section{REFERENCES CITED}

Askanian, H., Verney, V., Commereuc, S., Guyonnet, R., and Massardier, V. (2015). "Wood polypropylene composites prepared by thermally modified fibers at two extrusion speeds: Mechanical and viscoelastic properties," Holzforschung 69(3), 313319. DOI: $10.1515 / \mathrm{hf}-2014-0031$

ASTM D6110 (2010). "Standard test method for determining the Charpy impact resistance of notched specimens of plastics," ASTM International, West Conshohocken, PA.

ASTM D790 (2017). "Standard test methods for flexural properties of unreinforced and reinforced plastics and electrical insulating materials," ASTM International, West Conshohocken, PA.

Butylina, S., Martikka, O., and Kärki, T. (2015). "Weathering properties of coextruded polypropylene-based composites containing inorganic pigments," Polymer Degradation and Stability 120, 10-16. DOI: 10.1016/j.polymdegradstab.2015.06.004

Chen, L., Huang, R., Liu, X., Zhou, B., Xu, X., Wu, Q., Yang, X., and Shen, J. (2014). "Thermal decomposition kinetics of wood/rubber/HDPE composites," Journal of Nanjing Forestry University 38(6), 135-140.

Colom, X., Cañavate, J., Pages, P., Saurina, J., and Carrasco, F. (2000). "Changes in crystallinity of the HDPE matrix in composites with cellulosic fiber using DSC and FTIR," Journal of Reinforced Plastics and Composites 19(10), 818-830. DOI: 10.1106/8RMN-D1HE-75V1-7LN0

Gao, W., Ma, X., Liu, Y., Wang, Z., and Zhu, Y. (2013). "Effect of calcium carbonate on PET physical properties and thermal stability," Powder Technology 244, 45-51. DOI: 10.1016/j.powtec.2013.04.008

Huang, R., Mei, C., Xu, X., Krki, T., Lee, S., and Wu, Q. (2015). "Effect of hybrid talcbasalt fillers in the shell layer on thermal and mechanical performance of co-extruded wood plastic composites," Materials, 8(12): 8510-8523. DOI: 10.3390/ma8125473

Ibrahim, N. A., Yunus, W. M. Z. W., Abu-Ilaiwi, F. A., Rahman, M. Z. A., Ahmad, M. B., and Dahlan, K. Z. M. (2003). "Graft copolymerization of methyl methacrylate onto oil palm empty fruit bunch fiber using $\mathrm{H}_{2} \mathrm{O}_{2} / \mathrm{Fe}^{2+}$ as an initiator," Journal of Applied Polymer Science 89(8), 2233-2238. DOI: 10.1002/app.12467

Kim, B.-J., Yao, F., Han, G., Wang, Q., and Wu, Q. (2013). "Mechanical and physical properties of core-shell structured wood plastic composites: Effect of shells with hybrid mineral and wood fillers," Composites Part B: Engineering 45(1), 1040-1048. DOI: 10.1016/j.compositesb.2012.07.031

Koohestani, B., Ganetri, I., and Yilmaz, E. (2017). "Effects of silane modified minerals on mechanical, microstructural, thermal, and rheological properties of wood plastic composites," Composites Part B: Engineering 111, 103-111. DOI:

10.1016/j.compositesb.2016.12.021

Kord, B. (2011). "Investigation of reinforcing filler loading on the mechanical properties of wood plastic composites,” World Applied Sciences Journal 13(1), 171-174.

Li, M. and Wu, Z. H. (2013). "The properties of wood-plastics composite (WPC) and its 
application in furniture," Advanced Materials Research 815, 605-609. DOI:

10.4028/www.scientific.net/AMR.815.605

Li, P., Kim, B.-J., Wang, Q., and Wu, Q. (2013). "Experimental and numerical analysis of the sound insulation property of wood plastic composites (WPCs) filled with precipitated $\mathrm{CaCO}_{3}$," Holzforschung 67(3), 301-306. DOI: 10.1515/hf-2012-0093

Liao, Y. J., Yang, Q. S., and Wang, Y. J. (2012). "Application research of white mud in 660 MW unit FGD system," Advanced Materials Research 524-527, 940-944. DOI: 10.4028/www.scientific.net/AMR.524-527.940

Lin, J. H., Lin, Z. L., Chen, J. M., Fan, C. C., and Lou, C. W. (2014). "Manufacturing technique and mechanical property evaluations of polypropylene/short coir/short glass fiber wood plastic composites," Advanced Materials Research 910, 246-249. DOI: 10.4028/www.scientific.net/AMR.910.246

Mei, C., Sun, X., Wan, M., Wu, Q., Chun, S.-J., and Lee, S. Y. (2017). “Coextruded wood plastic composites containing recycled wood fibers treated with micronized copper-quat: Mechanical, moisture absorption, and chemical leaching performance," Waste Biomass Valorization 9(11), 1-8. DOI: 10.1007/s12649-017-9992-z

Mothé, C. G., and de Miranda, I. C. (2013). "Study of kinetic parameters of thermal decomposition of bagasse and sugarcane straw using Friedman and Ozawa-FlynnWall isoconversional methods," Journal of Thermal Analysis and Calorimetry 113(2), 497-505. DOI: 10.1007/s10973-013-3163-7

Nikolaeva, M., and Kärki, T. (2012). "Influence of mineral fillers on the fire-retardant properties of wood-polypropylene composites," Fire and Materials 37(8), 612-620. DOI: $10.1002 /$ fam.2160

Nikolaeva, M., and Kärki, T. (2016). "Influence of fire retardants on the reaction-to-fire properties of coextruded wood-polypropylene composites," Fire and Materials 40(4), 535-543. DOI: 10.1002/fam.2308

Nurdina, A. K., Mariatti, M., and Samayamutthirian, P. (2009). "Effect of single-mineral filler and hybrid-mineral filler additives on the properties of polypropylene composites," Journal of Vinyl and Additive Technology 15(1), 20-28. DOI: 10.1002/vnl.20173

Ou, R., Xie, Y., Wolcott, M. P., Sui, S., and Wang, Q. (2014). "Morphology, mechanical properties, and dimensional stability of wood particle/high density polyethylene composites: Effect of removal of wood cell wall composition," Materials \& Design 58(6), 339-345. DOI: 10.1016/j.matdes.2014.02.018

Pal, M. K., Singh, B., and Gautam, J. (2012). "Thermal stability and UV-shielding properties of polymethyl methacrylate and polystyrene modified with calcium carbonate nanoparticles," Journal of Thermal Analysis and Calorimetry 107(1), 8596. DOI: 10.1007/s10973-011-1686-3

Peng, P., and She, D. (2014). "Isolation, structural characterization, and potential applications of hemicelluloses from bamboo: A review," Carbohydrate Polymers 112,701-720. DOI: 10.1016/j.carbpol.2014.06.068

Poletto, M., Zattera, A. J., Forte, M. M. C., and Santana, R. M. C. (2012). "Thermal decomposition of wood: Influence of wood components and cellulose crystallite size," Bioresource Technology 109, 148-153. DOI: 10.1016/j.biortech.2011.11.122

Ritu, G., Noraziah, A., Gupta, A., and Abdalla, A. N. (2017). "Overview of simulation in wood plastic composites manufacturing," Indian Journal of Science and Technology 10(7), 1-5. DOI: 10.17485/ijst/2017/v10i7/111449

Sanchez-Garcia, M. D., Lagaron, J. M., and Hoa, S. V. (2010). "Effect of addition of 
carbon nanofibers and carbon nanotubes on properties of thermoplastic biopolymers," Composites Science and Technology 70(7), 1095-1105. DOI:

10.1016/j.compscitech.2010.02.015

Shi, X. B., Wang, J. L., Cai, X. P., and Zhang, S. (2013). "Role of calcium carbonate morphology on thermal and mechanical properties of HDPE," Plastics Rubber and Composites 42(7), 302-307. DOI: 10.1179/1743289813Y.0000000051

Vassiliou, A., Bikiaris, D., Chrissafis, K., Paraskevopoulos, K. M., Stavrev, S. Y., and Docoslis, A. (2008). "Nanocomposites of isotactic polypropylene with carbon nanoparticles exhibiting enhanced stiffness, thermal stability and gas barrier properties," Composites Science and Technology 68(3-4), 933-943. DOI: 10.1016/j.compscitech.2007.08.019

Vassiliou, A. A., Chrissafis, K., Bikiaris, D. N. (2010). “In situ prepared PET nanocomposites: Effect of organically modified montmorillonite and fumed silica nanoparticles on PET physical properties and thermal degradation kinetics," Thermochimica Acta 500(1-2), 21-29. DOI: 10.1016/j.tca.2009.12.005

Wu, Q., Chi, K., Wu, Y., and Lee, S. (2014). "Mechanical, thermal expansion, and flammability properties of co-extruded wood polymer composites with basalt fiber reinforced shells," Materials \& Design 60, 334-342. DOI: 10.1016/j.matdes.2014.04.010

Xian, Y., Li, H., Wang, C., Wang, G., Ren, W., and Cheng, H. (2015). "Effect of white mud as a second filler on the mechanical and thermal properties of bamboo residue fiber/polyethylene composites," BioResources 10(3), 4263-4276. DOI: 10.15376/biores. 10.3.4263-4276

Yao, F., and Wu, Q. (2010). "Coextruded polyethylene and wood-flour composite: Effect of shell thickness, wood loading, and core quality," Journal of Applied Polymer Science 118(6), 3594-3601. DOI: 10.1002/app.32742

Yao, F., Wu, Q., Lei, Y., Guo, W., and Xu, Y. (2008). "Thermal decomposition kinetics of natural fibers: Activation energy with dynamic thermogravimetric analysis," Polymer Degradation and Stability 93(1), 90-98. DOI: 10.1016/j.polymdegradstab.2007.10.012

Zaman, H. U., Khan, M. A., Khan, R.A., and Beg, M.D. (2014). "Effect of nano-CaCO 3 on the mechanical and crystallization behavior of $\mathrm{HDPE} / \mathrm{LDPE} / \mathrm{nano}-\mathrm{CaCO}_{3}$ ternary blend," Journal of Thermoplastic Composite Materials 27(12), 1701-1710. DOI: 10.1177/0892705712475010

Zhang, C., Li, K., and Simonsen, J. (2004). "Improvement of interfacial adhesion between wood and polypropylene in wood-polypropylene composites," Journal of Adhesion Science and Technology 18(14), 1603-1612. DOI: $10.1163 / 1568561042411330$

Article submitted: December 30, 2020; Peer review completed: February 7, 2021; Revised version received and accepted: February 21, 2021; Published: February 26, 2021. DOI: 10.15376/biores.16.2.2861-2875 